\title{
ANÁLISE DO PROCESSO DE IMPLANTAÇÃO DE BIM EM EMPRESAS DE PROJETOS INDUSTRIAIS E ARQUITETÔNICOS EM BELO HORIZONTE
}

\author{
ANAL YSIS OF THE IMPLEMENTATION PROCESS OF BIM IN INDUSTRIAL AND \\ ARCHITECTURAL DESIGNCOMPANIES INBELOHORIZONTE
}

\author{
Miguel Pereira Stehling \\ Eduardo Marques Arantes
}

\begin{abstract}
This paper presents an analysis of the Building Information Modeling implementation process in architectural and industrial design companies in Belo Horizonte. A field research was conducted interviewing professionals from industrial design and architectural design companies. The analysis was based on companies' characteristics and tools used. Also, it was evaluated how implementation occurred, resulting benefits, challenges faced and designers perception of the process. A diversified BIM tools use was observed in different specialties on industrial design while on architectural design it was observed hegemony of tools. It was observed that the implementation of BIM, in the studied universe, is more developed in industrial design than in architectural design. Industrial design companies are already in the interoperability implementation stage, which is a higher BIM level than in architectural design companies. Architectural design companies are in the effort of leaving the traditional two-dimensional drawings towards parameterized 3D models. It was noted that industrial designers have a higher value perception regarding to parametric issues than architectural designers. Regarding of major reasons for adopting BIM, the perception of value among industrial designers and architectural designers is similar.The perceptions on the barriers to the adoption of BIM are basically antagonic for industrial and architectural designers. The most common way of software learning occurs through tutorials, forums and collaboration between peers. Among the proposed improvements presented by the interviewees it stands out the collaboration in team work and the commitment from the top management.
\end{abstract}

Keywords: BIM. Industrial Design. Architectural Design.

Miguel Pereira Stehling

Centro Universitário Adventista de São Paulo (UNASP), Departamento de Engenharia Civil, Engenheiro Coelho - SP, miguel.stehling@unasp.edu.br

Eduardo Marques Arantes

Universidade Federal de Minas Gerais (UFMG), Departamento de Engenharia de Materiais e Construção, Belo Horizonte MG, arantes@demc.ufmg.br

\section{Introdução}

Segundo Dubois e Gadde (2002) a indústria da construção é um sistema de baixo acoplamento, isto é, suas entidades têm pouca ou nenhuma dependência entre si. Esta característica favorece a produtividade a curto prazo mas inibe a inovação e aprendizagem, resultando na ineficiencia do setor e consumo excessivo de energia e matéria prima.

Smith e Tardif (2009) afirmam que além de os problemas ambientais serem catalisadores de mudanças, também agregam um senso de urgência na solução da falha da indústria da construção em acompanhar os avanços tecnológicos e ganhos de produtividade experimentados por quase todas as outras indústrias.

Apesar da existência de novas opções de integração da informação oriundas da nova tecnologia de Modelagem da Informação da Construção (BIM), percebese como se trata de uma nova maneira de projetar e construir, os arquitetos, engenheiros, construtores, incorporadores e demais agentes envolvidos em um empreendimento, necessitam de uma estratégia (EASTMAN et al., 2008)

How to cite this article:

STEHLING, Miguel Pereira; ARANTES, Eduardo Marques. Análise do processo de implantação de BIM em empresas de projetos industriais e arquitetônicos em Belo Horizonte. PARC Pesquisa em Arquitetura e Construção, Campinas, v. 5, n.1, p. 35-44, jan./jun. 2014. 
O estudo apresentado é parte do resultado final de desenvolvimento de dissertação de mestrado na qual Stehling (2012) faz uma análise da utilização da tecnologia BIM em algumas empresas localizadas na cidade de Belo Horizonte. Foram analisadas comparativamente empresas de projetos industriais e empresas de projetos arquitetônicos residenciais e comerciais. O objetivo foi caracterizar: a forma de implantação dos processos BIM e os softwares associados; os principais benefícios da nova tecnologia para o processo de projeto, as barreiras, dificuldades e desafios encontrados pelas empresas.

\section{Fundamentação}

Segundo Smith e Tardif (2009), o principal desafio não é descobrir como implantar uma nova tecnologia, mas sim, como organizar e trocar as informações geradas no desenvolvimento de um empreendimento.

A elaboração de um planejamento bem documentado para a adoção de BIM contribui para que todos os agentes envolvidos estejam claramente cientes das oportunidades e responsabilidades associadas com a incorporação desta tecnologia ao processo de projeto. As empresas não deveriam questionar entre adotar ou não o BIM, mas sim definir em que áreas utilizar esta tecnologia e planejar detalhadamente a implantação. Dever-se-ia focar em implantar o BIM em nível necessário para maximizar o valor e minimizar custos e impactos de implantação (COMPUTER, 2012).

Uma boa tecnologia não deve substituir uma linha vital de comunicação e fluxo de trabalho, mas deve simplificálos minimizando ou eliminando tarefas e rotinas que não agregam valor e maximizando aquelas que agregam valor ao produto (KOSKELA, 2000).

Love, Gunasekaran e Li (1998), sugerem que em uma abordagem de equipes multidisciplinares os participantes devem se reunir durante o projeto para determinar como problemas a jusante podem ser afetados pelas decisões de projeto.

Arantes, Homero Junior e D’Almeida (2011) atribuem ao projeto um caráter de processo e entendem a gestão do projeto como um conjunto de atividades coordenadas de um sistema aliadas a um eficiente sistema de gerenciamento de dados e informações. Nesse contexto, a adoção de sistemas colaborativos é uma ferramenta de auxílio na gestão do processo de projeto.

Tobin (2008) entende que a implantação do BIM se materializa em três fases chamadas de BIM 1.0, BIM 2.0 e BIM 3.0. A fase BIM 1.0 é denominada " $C A D$ on Steroids"; incorpora a modelagem 3D orientada a objetos com objetivo de melhorar a coordenação e agilizar a produção da documentação. A fase BIM 2.0 é denominada "The Big Bang in Reverse", amplia o universo de modelagem orientada a objeto para todos os agentes da construção civil, incorpora diferentes usos do modelo de informação além da representação como análises de desempenho, planejamento e gestão de facilidades. Nesta fase, modelos de diversas disciplinas são consolidados em um único modelo. Assim, BIM 2.0 depende da interoperabilidade, isto é, do reuso do modelo de informação entre ferramentas computacionais. Finalmente, a fase BIM 3.0 é denominada "PostInteroperability”, incorpora o conceito de modelos BIM, como "protobuildings" construídos colaborativamente em rede.

Tobin (2008) não é o único que preconiza que a adoção de BIM se dá por etapas que crescem em complexidade. Succar (2009) também descreve a implantação de BIM em três estágios muito similares aos anteriormente apresentados: (1) da modelagem orientada a objetos, (2) da colaboração e (3) da integração em rede. Esta estratificação tem sido adotada para caracterizar e diagnosticar processo de adoção de BIM tanto na prática (KHOSROWSHAHI; ARAYICI, 2012) como no ensino (RUSCHEL; ANDRADE; MORAIS, 2013).

\section{Método de pesquisa}

As análises são concernentes ao fluxo da informação, bem como do processo de produção dos projetos e da relação das empresas com o setor de produção. Foram pesquisados: a forma de implantação dos processos BIM e os softwares associados; os principais benefícios da nova tecnologia para o processo de projeto, as barreiras, dificuldades e desafios encontrados pelas empresas.

Quanto aos procedimentos, o método utilizado foi Estudo de Campo. Quanto aos objetivos, este estudo pode ser classificado como descritivo, ao fornecer informações sobre as distribuições das características dos indivíduos selecionados e entrevistados. Foram utilizados questionários enviados por meio de correio eletrônico e realizaram-se entrevistas presenciais, tendo por base um roteiro. O questionário utilizado na pesquisa online foi reaplicado nas entrevistas. Além disto, aprofundou-se o questionamento das entrevistas com um roteiro específico. As entrevistas foram gravadas com a anuência dos entrevistados e transcritas para facilitar a análise dos dados, e uma comparação entre as informações obtidas pelos dois meios de pesquisa utilizados.

O questionário aplicado no levantamento online continha duas partes: a primeira de caracterização e a segunda de levantamento de opinião. As questões sobre 
caracterização eram relativas a: formação do entrevistado, a familiaridade com BIM, as ferramentas utilizadas e sobre o conhecimento de ferramentas BIM específicas. O levantamento de opinião (por meio de pontuação) era relativo a: importância da parametrização, dos motivos para adoção de BIM; dos impedimentos para a adoção de BIM; do envolvimento da empresa no processo de adoção de BIM e dos desafios para a implantação de BIM. Para cada questão de opinião, listou-se aspectos diversos que remetiam a produtos/benefícios da implantação de BIM. Para cada aspecto o respondente deveria atribuir a importância percebida pelo mesmo estabelecendo uma nota de zero a dez.

O roteiro aplicado na entrevista identificava: a área de atuação do entrevistado, sua familiaridade com a tecnologia BIM, softwares BIM em utilização pelos mesmos e processo de aprendizagem. Além disto, levantou-se a opinião, por meio de pontuação de 0 a 10 dos seguintes aspectos: dificuldades, motivação, mudanças vivenciadas e benefícios percebidos.

A análise dos resultados se deu comparativamente entre os dois universos estudados: do projeto na indústria da mineração e do projeto de arquitetura e engenharia na construção civil.

\section{Caracterização da amostra da pesquisa online e das entrevistadas}

\section{Pesquisa online}

Fizeram-se consultas por meio de $e$-mails e telefonemas, às entidades representativas ${ }^{1}$ de empresas e profissionais de arquitetura, engenharia e construção de Belo Horizonte identificando o objetivo acadêmico da pesquisa e solicitando que a entidade fornecesse uma lista de associados ou enviasse o questionário aos respectivos membros, associados e colaboradores. Em alguns casos a lista de associados foi fornecida e em outros a própria entidade encaminhou o questionário para aplicação entre seus associados. O questionário foi também enviado para profissionais dentre os contatos pessoais dos autores da pesquisa, notadamente na área de projetos industriais. Desta forma foram enviados os questionários para 121 profissionais conforme mostra o Quadro 1. Dentre estes, 8 não receberam o questionário por possuírem sistemas antispam em seus e-mails. Deste esforço, obteve-se um retorno de respostas de 36 questionários representando aproximadamente $5 \%$ do universo de associados destas entidades. Os profissionais ou empresas respondentes foram contactados e convidados para uma conversa presencial, cuja finalidade era obter informações mais detalhadas. Entre estes, 16 aceitaram o convite e formaram a amostra de entrevistados.

A área de atuação das empresas pesquisadas dividiu-se em dois grupos: no primeiro grupo empresas de projetos industriais, e no segundo grupo empresas de projetos arquitetônicos residenciais e comerciais. Houve uma representatividade diferente entre as amostras do primeiro e segundo grupo. Todo o universo das empresas do primeiro grupo foi contactado, enquanto a população das empresas do segundo grupo foi abordada pelo método descrito no parágrafo anterior.

Quadro 1. Percentuais da coleta de dados

\begin{tabular}{|c|c|c|}
\hline$\%$ & Amostra & Histórico \\
\hline $\mathbf{2 9 , 8} \%$ & 36 & Responderam ao questionário \\
\hline $\mathbf{6 , 6} \%$ & 8 & Não responderam por não receberem o email \\
\hline $\mathbf{5 0 , 4 \%}$ & 61 & Não desejaram participar da pesquisa \\
\hline $\mathbf{1 3 , 2} \%$ & 16 & $\begin{array}{c}\text { Responderam questionário e concederam } \\
\text { entrevista }\end{array}$ \\
\hline $\mathbf{1 0 0 , 0 \%}$ & 121 & Total de profissionais contactados \\
\hline
\end{tabular}

Fonte:Stehling(2012)

\section{Profissionais entrevistados e empresas associadas}

Foram entrevistados 16 profissionais em 12 empresas, sendo 7 empresas de projetos industriais e 5 empresas de projetos arquitetônicos conforme mostra o Quadro 2. O Quadro 3 apresenta a caracterização das empresas associadas aos entrevistados, no qual se apresenta o ano de fundação, tipos de projeto que a empresa executa, perfil de seus principais clientes, as disciplinas nas quais possui equipes de projetos, bem como outras características relevantes no contexto desta pesquisa.

Quadro 2. Funções dos entrevistados

\begin{tabular}{|c|c|c|c|}
\hline & Empresa & $\begin{array}{c}\text { Entrevis } \\
\text { tado }\end{array}$ & Função \\
\hline \multirow{10}{*}{$\begin{array}{l}\frac{1}{3} \\
\frac{\hat{p}}{2} \\
\frac{3}{3} \\
\underline{2}\end{array}$} & \multirow{2}{*}{ A } & A1 & Projetista e analista de suporte de TI \\
\hline & & A2 & Especialista em modelamento \\
\hline & \multirow{3}{*}{ B } & B1 & Gerente de TI \\
\hline & & B2 & Engenheiro especialista em TI \\
\hline & & B3 & Suporte técnico em BIM \\
\hline & C & $\mathrm{C} 1$ & Projetista de estruturas metálicas \\
\hline & D & D1 & Engenheiro sócio fundador da empresa \\
\hline & $E$ & E1 & Engenheiro projetista \\
\hline & $\mathrm{F}$ & F1 & Engenheiro projetista \\
\hline & G & G1 & Projetista \\
\hline \multirow{6}{*}{$\begin{array}{l}8 \\
0 \\
z \\
0 \\
=5 \\
\frac{0}{0} \\
\frac{9}{4}\end{array}$} & $\mathrm{H}$ & $\mathrm{H} 1$ & Arquiteto \\
\hline & $\mathrm{J}$ & $\mathrm{J1}$ & Arquiteto gerente de projetos \\
\hline & K & K1 & Arquiteto socio fundador da empresa \\
\hline & $\mathrm{L}$ & L1 & Engenheiro e arquiteto \\
\hline & \multirow{2}{*}{ M } & M1 & Arquiteto \\
\hline & & M2 & Arquiteto gerente de projetos \\
\hline
\end{tabular}

Fonte:Stehling(2012) 
Quadro 3. Características das empresas entrevistadas

\begin{tabular}{|c|c|c|c|c|c|c|}
\hline & $\begin{array}{l}\text { Emp } \\
\text { resa }\end{array}$ & $\begin{array}{l}\text { Ano de } \\
\text { fundação }\end{array}$ & Tipos de projetos & Perfil dos clientes & Equipes de projeto & Outras características \\
\hline \multirow{7}{*}{$\begin{array}{l}\text { I } \\
\text { N } \\
\text { D } \\
\text { U } \\
S \\
T \\
R \\
\text { I } \\
A \\
\text { L }\end{array}$} & A & $\begin{array}{l}\text { Fundada a } \\
\text { mais de } 100 \\
\text { anos }\end{array}$ & $\begin{array}{l}\text { Projetos industriais } \\
\text { multidisciplinares, } \\
\text { gestão integral de } \\
\text { projetos }\end{array}$ & $\begin{array}{l}\text { Indústrias de mineração, } \\
\text { metalurgia, siderurgia, } \\
\text { equipamentos e edifícios } \\
\text { industriais }\end{array}$ & $\begin{array}{l}\text { Equipes multidisciplinares: } \\
\text { arquitetura, estruturas, } \\
\text { mecânica, tubulação, } \\
\text { caldeiraria, instalações }\end{array}$ & $\begin{array}{l}\text { Assume gestão de projetos de } \\
\text { equipamentos e plantas desde o } \\
\text { planejamento até o início das } \\
\text { operações }\end{array}$ \\
\hline & B & $\begin{array}{l}\text { Década de } \\
70\end{array}$ & $\begin{array}{l}\text { Projetos industriais } \\
\text { multidisciplinares, } \\
\text { gerenciamento de } \\
\text { empreendimentos }\end{array}$ & $\begin{array}{l}\text { Indústrias de mineração, } \\
\text { metalurgia, siderurgia, óleo, } \\
\text { gás e infraestrutura, } \\
\text { celulose, energia, portos e } \\
\text { estaleiros }\end{array}$ & $\begin{array}{l}\text { Equipes multidisciplinares: } \\
\text { arquitetura, estruturas, } \\
\text { mecânica, tubulação, } \\
\text { caldeiraria, instalações }\end{array}$ & $\begin{array}{l}\text { Gerenciamento de implantação } \\
\text { de empreendimentos para } \\
\text { empresas de grande porte. No } \\
\text { escritório de Belo Horizonte } \\
\text { predominam projetos para } \\
\text { indústrias siderúrgicas e de } \\
\text { mineração } \\
\end{array}$ \\
\hline & C & $\begin{array}{l}\text { Década de } \\
80\end{array}$ & $\begin{array}{l}\text { Projetos industriais } \\
\text { multidisciplinares, de } \\
\text { pequeno, médio e } \\
\text { grande porte }\end{array}$ & $\begin{array}{l}\text { Indústrias de mineração, } \\
\text { metalurgia, siderurgia, obras } \\
\text { civis industriais, indústrias de } \\
\text { cimento e petroquímica }\end{array}$ & $\begin{array}{l}\text { Equipes multidisciplinares: } \\
\text { arquitetura, estruturas, } \\
\text { mecânica, tubulação, } \\
\text { instrumentação industrial e } \\
\text { instalações elétricas } \\
\text { industriais } \\
\end{array}$ & $\begin{array}{l}\text { Consultoria, engenharia e } \\
\text { geotecnia. No escritório de Belo } \\
\text { Horizonte predominam projetos } \\
\text { para indústrias de mineração }\end{array}$ \\
\hline & D & $\begin{array}{l}\text { Década de } \\
80\end{array}$ & $\begin{array}{l}\text { Projetos industriais: } \\
\text { instalações e } \\
\text { equipamentos } \\
\text { industriais }\end{array}$ & $\begin{array}{c}\text { Equipamentos, sistemas e } \\
\text { estruturas para indústrias de } \\
\text { bens de capital. Mineração, } \\
\text { Siderurgia, metalurgia e } \\
\text { cimento. }\end{array}$ & $\begin{array}{l}\text { Equipes multidisciplinares: } \\
\text { estruturas metálicas, } \\
\text { mecânica, tubulação, } \\
\text { estruturas de concreto e } \\
\text { saneamento básico }\end{array}$ & $\begin{array}{l}\text { Gerenciamento e execução de } \\
\text { projetos industriais; } \\
\text { Planejamento e controle de } \\
\text { custos. Fornece serviços de } \\
\text { alocação de mão de obra } \\
\text { especializada. }\end{array}$ \\
\hline & E & $\begin{array}{l}\text { Década de } \\
60\end{array}$ & $\begin{array}{l}\text { Projetos industriais } \\
\text { multidisciplinares, e } \\
\text { engenharia consultiva }\end{array}$ & $\begin{array}{l}\text { Siderurgia, Mineração, } \\
\text { Metalurgia, infraestrutura, } \\
\text { gás natural, petróleo e } \\
\text { celulose }\end{array}$ & $\begin{array}{l}\text { Equipes multidisciplinares: } \\
\text { estruturas, arquitetura, } \\
\text { mecânica, tubulação, } \\
\text { instalações }\end{array}$ & $\begin{array}{l}\text { Bens de capital, estudos de } \\
\text { viabilidade e consultoria, gestão } \\
\text { integradora de parcerias, } \\
\text { auditorias em equipamentos } \\
\text { industriais. }\end{array}$ \\
\hline & $F$ & $\begin{array}{l}\text { Década de } \\
70\end{array}$ & $\begin{array}{l}\text { Engenharia de projetos } \\
\text { de instalações e } \\
\text { equipamentos } \\
\text { industriais; apoio } \\
\text { técnico à implantação } \\
\text { de empreendimentos. } \\
\end{array}$ & $\begin{array}{l}\text { Edifícios, instalações e } \\
\text { equipamentos de mineração } \\
\text { e siderurgia; nacionalização } \\
\text { de projetos estrangeiros. }\end{array}$ & $\begin{array}{l}\text { Equipes multidisciplinares; } \\
\text { Arquitetura, Estruturas, } \\
\text { Mecânica, tubulação e } \\
\text { elétrica }\end{array}$ & $\begin{array}{l}\text { Consultoria de projetos } \\
\text { conceitual, básico e executivo; } \\
\text { fiscalização de obra e gestão da } \\
\text { qualidade; projetos de } \\
\text { manutenção }\end{array}$ \\
\hline & G & $\begin{array}{l}\text { Década de } \\
80\end{array}$ & $\begin{array}{l}\text { Projetos industriais } \\
\text { multidisciplinares, } \\
\text { conceituais, viabilidade, } \\
\text { apoio a suprimentos, } \\
\text { construcao, montagem }\end{array}$ & $\begin{array}{l}\text { Mineracao e metalurgia; } \\
\text { empresas nacionais ou } \\
\text { globais }\end{array}$ & $\begin{array}{l}\text { Equipes multidisciplinares: } \\
\text { Geologia, Processos, } \\
\text { Estruturas, mecânica, } \\
\text { tubulação, eletrica, } \\
\text { Instrumentacao e Controle } \\
\end{array}$ & $\begin{array}{l}\text { Consultorias, pre-operacao e } \\
\text { posta-em-marcha de intalacoes, } \\
\text { engenharia basica e detalhada }\end{array}$ \\
\hline \multirow{5}{*}{$\begin{array}{l}A \\
R \\
Q \\
U \\
I \\
T \\
E \\
T \\
O \\
N \\
I \\
C \\
O\end{array}$} & H & 2004 & $\begin{array}{l}\text { Projetos Residenciais e } \\
\text { comerciais, de pequeno, } \\
\text { medio e grande porte }\end{array}$ & $\begin{array}{c}\text { Empreendimentos turisticos, } \\
\text { institucionais, Imobiliario, } \\
\text { Shoppings, Entretenimento e } \\
\text { Infraestrutura }\end{array}$ & $\begin{array}{l}\text { Arquitetura, Urbanismo, } \\
\text { Engenharia Civil e eletrica, }\end{array}$ & $\begin{array}{l}\text { Gestao de projetos, Convênios } \\
\text { com instituições de ensino para } \\
\text { Pesquisa, Desenvolvimento e } \\
\text { Inovação; "Lean Production" }\end{array}$ \\
\hline & J & 1981 & $\begin{array}{c}\text { Projetos Residenciais e } \\
\text { comerciais, de pequeno, } \\
\text { medio e grande porte; } \\
\text { Cross-docking, } \\
\text { armazem logistico } \\
\end{array}$ & $\begin{array}{l}\text { Empreendedores imobiliarios } \\
\text { dos setores de logística, } \\
\text { Indústria e Comercio }\end{array}$ & $\begin{array}{l}\text { Arquitetura, Engenharia } \\
\text { Civil e eletrica, }\end{array}$ & $\begin{array}{l}\text { Construção e administração de } \\
\text { imóveis; centros de comercio, } \\
\text { centros de distribuicao }\end{array}$ \\
\hline & K & 2007 & $\begin{array}{c}\text { Projetos Residenciais e } \\
\text { comerciais; } \\
\text { Treinamento e } \\
\text { consultoria }\end{array}$ & $\begin{array}{l}\text { Projetos de pequeno e } \\
\text { medio porte para pessoas } \\
\text { fisicas e Juridicas }\end{array}$ & $\begin{array}{c}\text { Arquitetura e coordenacao } \\
\text { de projetos }\end{array}$ & $\begin{array}{c}\text { Centro de treinamento e } \\
\text { pesquisa em softwares no setor } \\
\text { de construcao civil }\end{array}$ \\
\hline & L & 1994 & $\begin{array}{c}\text { Arquitetura de } \\
\text { interiores, Projetos } \\
\text { executivos e } \\
\text { detalhamento; } \\
\text { especificacao de } \\
\text { materiais } \\
\end{array}$ & $\begin{array}{c}\text { Projetos Residenciais e } \\
\text { comerciais, Processos de } \\
\text { Projetos }\end{array}$ & $\begin{array}{l}\text { Arquitetura, Engenharia } \\
\text { civil }\end{array}$ & $\begin{array}{c}\text { Arquitetura e Planejamento, } \\
\text { Sustentabilidade, Certificação de } \\
\text { edificações }\end{array}$ \\
\hline & M & 2005 & $\begin{array}{l}\text { Projetos Residenciais e } \\
\text { comerciais; Urbanismo; } \\
\text { Engenharia simultanea, }\end{array}$ & $\begin{array}{l}\text { Projetos de pequeno e } \\
\text { medio porte para pessoas } \\
\text { fisicas e Juridicas }\end{array}$ & $\begin{array}{l}\text { Arquitetura, instalacoes } \\
\text { eletricas, hidrosanitarias, } \\
\text { estrutural, incendio, } \\
\text { climatizacao, }\end{array}$ & $\begin{array}{c}\text { Estudos de viabilidade, } \\
\text { certificacao verde, licenciamento } \\
\text { ambiaental }\end{array}$ \\
\hline
\end{tabular}

Fonte: Adaptado de Stehling(2012) 


\section{Resultado e discussão da pesquisa online}

\section{Familiaridade com BIM}

Conforme mostra o Gráfico 1, dentre os 36 respondentes da pesquisa online, $72,7 \%$ dos profissionais de projetos industriais afirmaram categoricamente que trabalham com a tecnologia BIM, caracterizando uma disparidade em relação aos $28,6 \%$ dos profissionais de projetos arquitetônicos residenciais e comerciais que afirmaram trabalhar com BIM. A não familiaridade dos profissionais de projetos arquitetônicos é confirmada pelo fato de que $7,1 \%$ apenas "ouviu falar" e $21,4 \%$ que reconhecem que "nunca ouviu falar" sobre o tema. O quesito "Apenas leu sobre o assunto" foi marcado por $42,9 \%$ dos respondentes de projetos arquitetônicos. Este resultado está em sintonia com a afirmação de Becerik-Gerber e Kensek (2010) de que a publicidade em torno de BIM é enorme, mas na realidade as metas já alcançadas, observada neste estudo, são limitadas.

Gráfico 1. Familiaridade com BIM

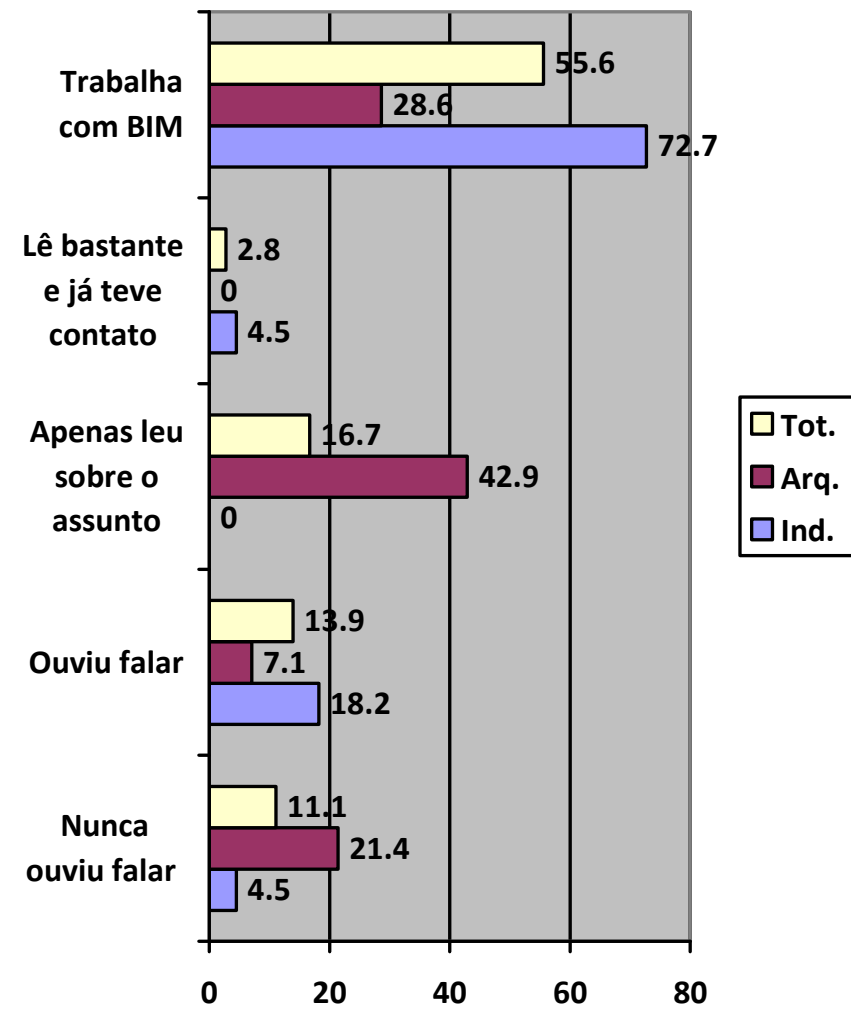

Fonte: Adaptado de Stehling(2012)

Procurou-se identificar o processo de implantação da tecnologia BIM, e observou-se que $91 \%$ das mudanças começam testando-se um modelo de um edifício cujo projeto tradicional 2D já havia sido desenvolvido ou estava em fase de desenvolvimento ou implantação. Este método permitia que se fizesse comparativos e se adquirisse confiança progressiva na nova tecnologia. A análise dos questionários e as informações obtidas nas entrevistas presenciais dão indícios de que há insegurança dos projetistas quanto a implantar BIM através da criação de um modelo de uma edificação cujo projeto previamente não tenha sido desenvolvido na forma tradicional 2D.

\section{Utilização de Ferramentas BIM}

Nas empresas de projetos arquitetônicos residenciais e comerciais predominam os softwares Revit $(53,1 \%)$ e ArchiCAD (21,9\%), enquanto nas empresas de projetos industriais não há tanta hegemonia, sendo Revit (16,7\%), Tekla (18,8\%), Smartplant(15,6\%), PDMS (14,6\%), Inventor $(9,4 \%)$ e Solidworks(6,3\%) os principais softwares utilizados, conforme mostra o Gráfico 2.

Gráfico 2. Softwares mais utilizados

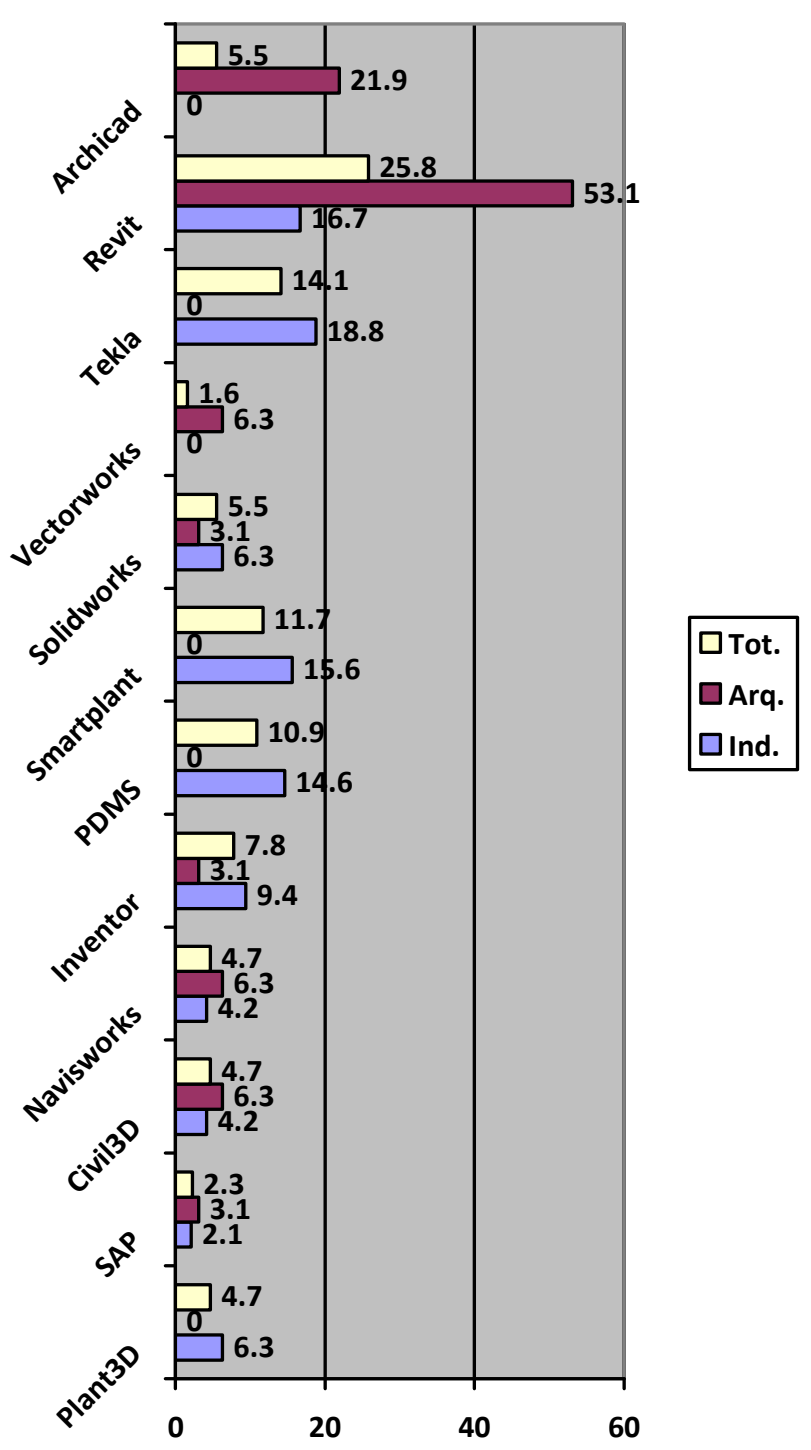

Fonte: Stehling(2012) 
Verificou-se que muitos projetistas aplicam conceitos BIM em seus projetos, mas desconhecem as terminologias da tecnologia.

Todas as empresas de projetos arquitetônicos residenciais e comerciais que fazem compatibilização dos modelos, disseram que utilizam o software Navisworks, enquanto nas empresas de projetos industriais, as empresas fazem compatibilização dos modelos utilizando os softwares Navisworks, Smartplant e PDMS.

\section{Parametrização}

Algumas questões foram formuladas acerca de uma das principais características da tecnologia BIM, que é a parametrização. O Gráfico 3 apresenta o resultado da opinião dos respondentes da pesquisa online, que classificaram com nota zero(0) as características pouco significativas, e com nota $\operatorname{dez}(10)$ as características muito significativas.

Os respondentes que trabalham em empresas de projetos arquitetônicos têm uma percepção de valor menor com relação à parametrização, do que os de projetos industriais, excessão feita ao ítem "Dimensionamento vinculado à geometria" que apresentou uma inversão de valores. Este tópico está relacionado a uma prática comum quando se fazem revisões em projetos $2 \mathrm{D}$, que consiste em alterar o texto de uma dimensão sem alterar o objeto, sendo esta uma fonte de erros tanto de projeto quanto construção. Esta prática é impossível em ferramentas de modelagem BIM, pois 0 dimensionamento é um parâmetro do objeto.

Os quesitos "Objetos podem transferir ou receber atributos de outras aplicações" e "Geometria associada a especificações, custo e tempo" apresentaram percepção similar tanto por respondentes de projetos industriais quanto de projetos arquitetônicos.

O quesito "Níveis hierárquicos dos objetos" mostrado no Gráfico 3 recebeu nota máxima em empresas de projetos industriais (nota 10,0), embora seja ainda um benefício pouco percebido por empresas de projetos arquitetônicos residenciais e comerciais (nota 5,3).

Dentre os benefícios mais valorizados está "Geometria definida por parâmetros”, embora a obtenção deste benefício ainda seja dificultada pela inexistência de biblioteca de componentes dos produtos utilizados na construção brasileira.

Gráfico 3. Importância da parametrização

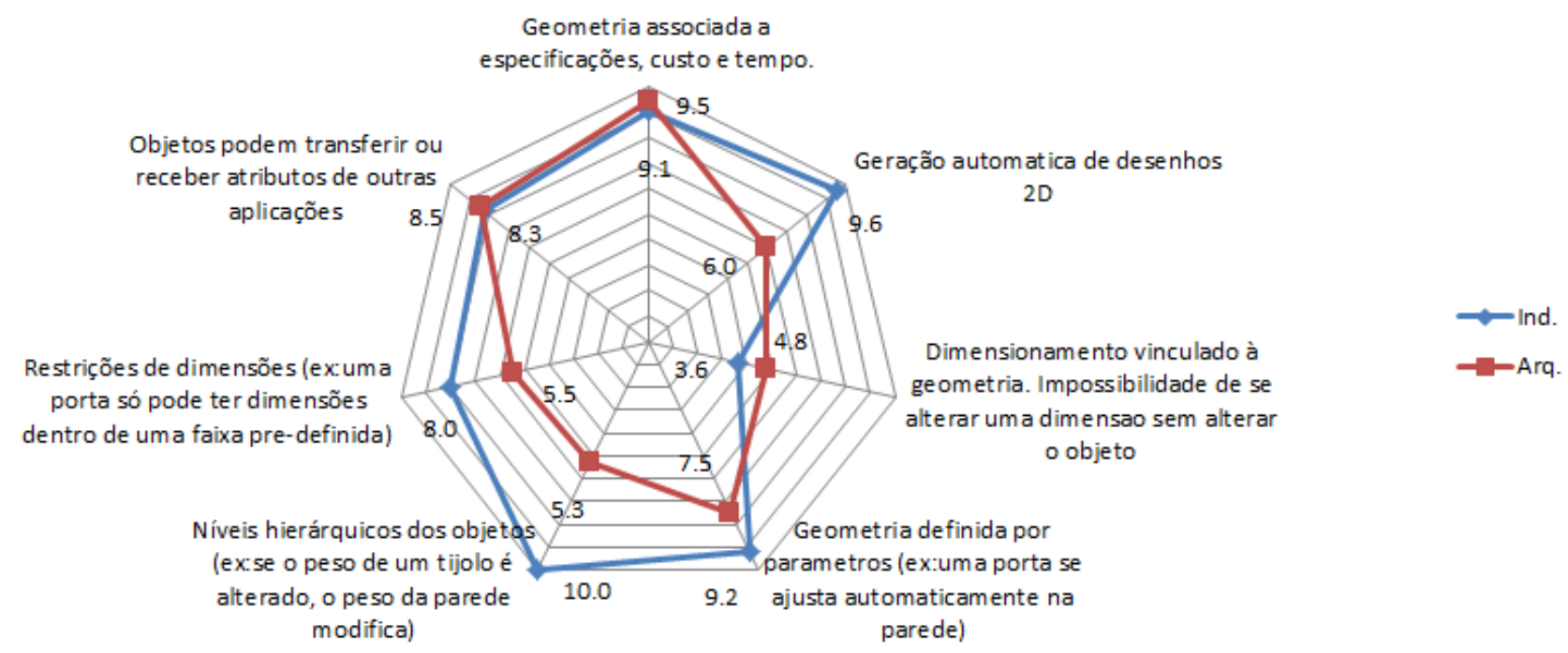

Fonte: Adaptado de Stehling(2012)

\section{Motivos importantes para se adotar BIM}

Procurou-se, na investigação, a classificação dos motivos para se adotar a tecnologia BIM, solicitando-se notas de 0(zero) a 10(dez) para benefícios pouco importantes e benefícios muito importantes, respectivamente.

Conforme apresentado no Gráfico 4, em termos de motivos importantes para se adotar BIM, a percepção de valor entre os participantes do questionário online, comparativamente entre projetos industrials $\mathrm{e}$ arquitetônicos é similar. Apenas nos quesitos "Parceriaprojetistas, construtores, fornecedores” e "interoperabilidade" existem diferenças de percepção. A menor percepção de valor destes ítens por parte dos profissionais de arquitetura é reflexo destes ainda estarem na fase inicial de implantação da tecnologia BIM. 
Os quesitos "Facilidade de compatibilização de projetos", "Lista de materiais e orçamentos", e "Bons tutoriais e fontes de aprendizado" são os que obtiveram maior percepção de valor A análise desses números confirma que os benefícios mais importantes estão relacionados à qualidade. Vale ressaltar que profissionais de projetos industriais valorizaram mais a "Melhor vizualização pelo cliente" por meio da utilização de modelos tridimensionais (nota 8,6), embora clientes de projetos industriais sejam em geral tecnicamente mais capacitados em fazer leituras dos tradicionais documentos técnicos 2D do que clientes de projetos arquitetônicos.
Embora ao classificar a importância da parametrização (Gráfico 3), todos os respondentes tenham atribuído valor elevado ao quesito "Objetos podem transferir ou receber atributos de outras aplicações”, ao classificarem os motivos importantes para se adotar BIM (Gráfico 4), os respondentes de arquitetura atribuíram um valor apenas razoável ao quesito "Interoperabilidade".

O quesito "software com hegemonia de mercado" foi considerado pouco importante para projetos industriais e para projetos arquitetônicos (notas 5,1 e 4,5 respectivamente).

Gráfico 4. Motivos importantes para se adotar BIM

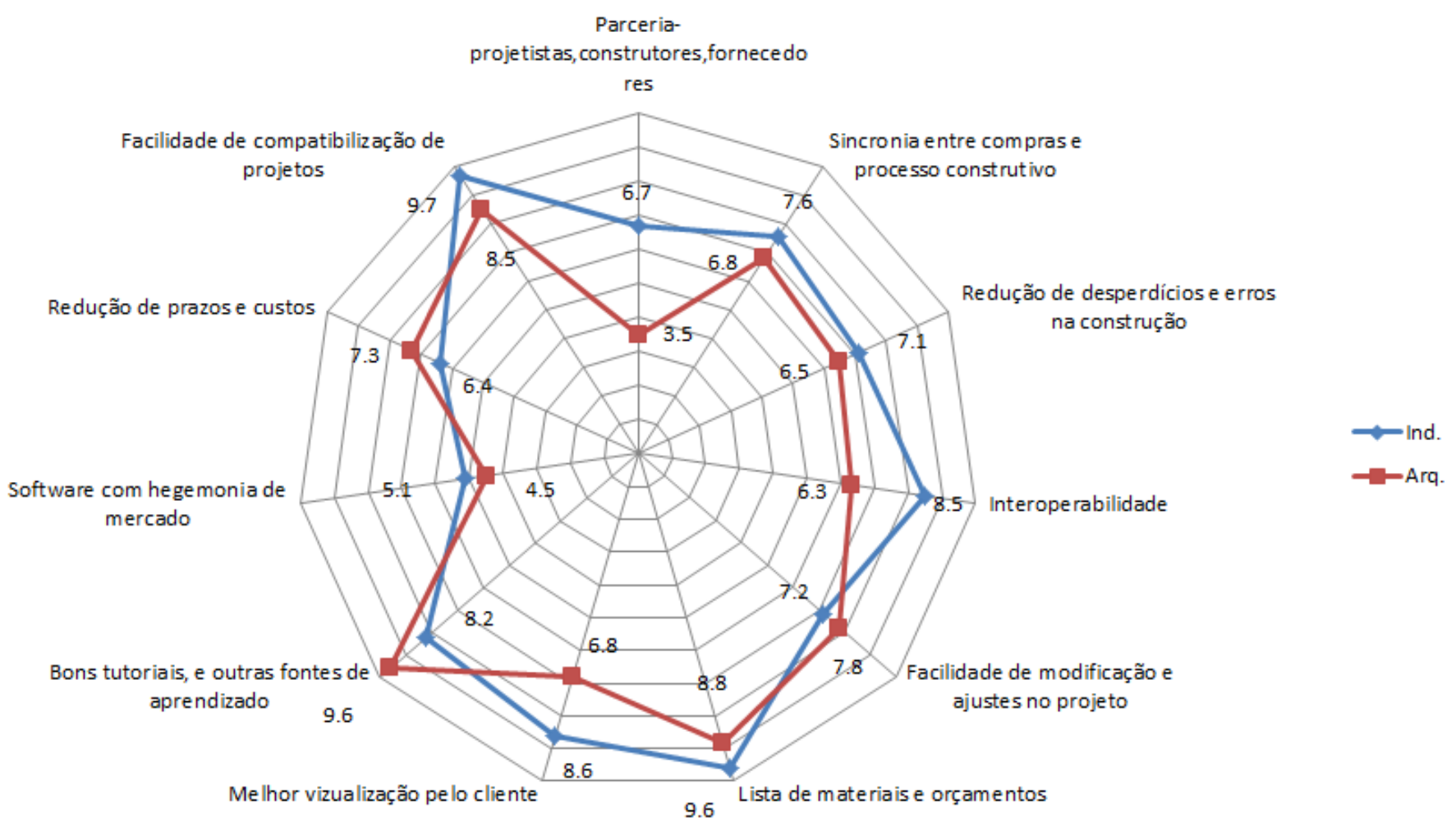

Fonte: Adaptado de Stehling(2012)

A percepção reduzida ao valor do ítem "Parcerias entre projetistas, construtores e fornecedores" por parte de empresas de projetos arquitetônicos residenciais e comerciais, mostra que estas empresas ainda não perceberam que uma das principais vantagens do BIM é a integração dos agentes da construção. A visão destes projetistas ainda se volta apenas para a melhoria no setor de projeto em si, não necessariamente para o setor da construção como um todo.

Embora seja importante para as empresas o cumprimento de prazos contratuais de execução de projetos, observa-se entre os respondentes da pesquisa online uma importância razoável ao quesito "Redução de custos e prazos" (notas 6,4 e 7,3 respectivamente para projetos industriais e projetos arquitetônicos)
A análise mostra que os benefícios decorrentes da interoperabilidade são mais valorizados por empresas de projetos industriais (nota 8.5) do que por empresas de arquitetura (nota 6,3). Estes resultados são indícios de que empresas de projetos industriais já se encontram em direção à fase BIM 2.0, que conforme Tobin (2008) é a fase da interoperabilidade.

\section{Impedimentos para se adotar BIM}

Procurou-se, na investigação, a classificação dos impedimentos para se adotar a tecnologia BIM, da seguinte forma: nota 0 (zero) equivalente a nenhuma dificuldade e a nota 10 (dez) a muita dificuldade. 
Conforme apresentado no Gráfico 4, as percepções sobre os impedimentos para a adoção de BIM entre projetistas industriais e projetistas arquitetônicos são basicamente antagônicas, sendo coincidentes apenas nos quesitos "Custo elevado do software", "Tecnologia muito complexa”, "Falta de mão de obras especializada" e "Pouca interação entre universidades, empresas e governo".

É interessante notar que os respondentes consideraram como impedimento pouco significativo o quesito "Tecnologia muito complexa”.
A análise do Gráfico 5 mostra que o custo de softwares é um desafio menos significativo para empresas de projetos industriais (nota 6,5) do que para empresas de projetos arquitetônicos (nota 7,3).

As empresas de projetos industriais estão em um nível de desenvolvimento que requer interoperabilidade, o que conforme Tobin (2008) é a fase BIM 2.0. O quesito "Incompatibilidade com outros programas", no Gráfico 5, confirma este fato ao apresentar nota 5,3 para projetos industriais e nota 3,0 para projetos arquitetônicos. As empresas de projetos industriais apresentam este quesito como um desafio na implantação BIM.

Gráfico 5. Impedimentos para se adotar BIM

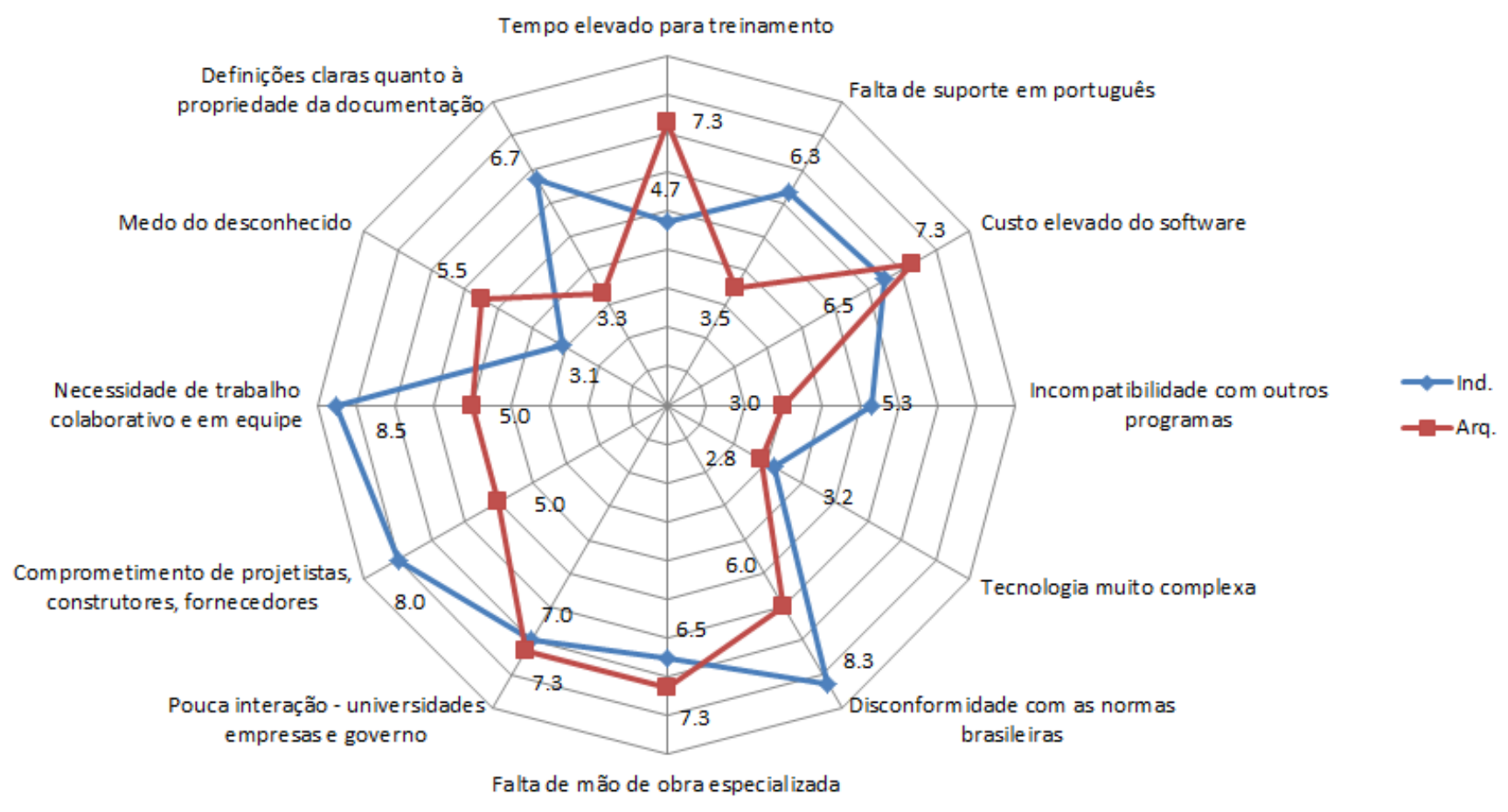

Fonte: Adaptado de Stehling(2012)

\section{Resultado e discussão das entrevistas}

Dentre os 36 profissionais que responderam ao questionário online, 16 concederam também entrevistas que foram gravadas com a anuência dos entrevistados e transcritas para facilitar as análises.

Ao classificar as dificuldades encontradas na implantação do BIM, 43,8\% dos entrevistados apontaram a utilização de softwares, enquanto $56,3 \%$ ressaltaram os processos de projeto e construção. Estas respostas estão em harmonia com a premissa básica apontada pela revisão bibliográfica de que o BIM não é um novo software, mas uma nova maneira de construir.

Os desafios apontados para a implantação do BIM, podem ser agrupados em desafios relativos à utilização de softwares, notadamente a interoperabilidade, e os desafios relativos a processos de projeto e construção, onde se destaca a necessidade de trabalho colaborativo.

A necessidade de mudança no processo de projeto tem sido um grande desafio para se implantar a tecnologia BIM em várias empresas. As empresas têm tido maior progresso na implantação do BIM através da liderança dos novos profissionais, que têm facilidade para trabalhar com ferramentas 3D, aprender utilizando tutoriais e consultar fóruns na Internet.

Foi apontado também como desafio a geração da biblioteca de objetos necessários para a construção dos modelos. Este é um trabalho que consome muito tempo e deixa os líderes do projeto ansiosos quanto ao cumprimento de prazos e orçamentos. 
As empresas afirmaram que a implantação desta nova tecnologia é difícil e longa, não somente pelo tempo necessário para o aprendizado de novos softwares, mas também por requerer dos projetistas o conhecimento de detalhes construtivos. Ao se começar a trabalhar com o BIM, surgem na fase de projeto, muitos problemas que no processo tradicional de projetação só eram identificados na obra.

As empresas de arquitetura enfrentam mais dificuldades do que as empresas de projetos industriais no que tange ao elevado investimento necessário para o licenciamento de softwares e aquisição de hardware, o que para as empresas de arquitetura, representa uma porcentagem significativa do orçamento da empresa.

A observação feita por Pazlar e Turk (2008) de que as ferramentas BIM ainda necessitam de melhorias nos protocolos de comunicação de dados é confirmada pelos entrevistados que afirmaram que os softwares interagem diferentemente entre si.

Verificou-se nas entrevistas, que em projetos industriais as ferramentas são escolhidas pelas suas características, e não pelo que outras empresas adotam. Verificou-se também que cada disciplina cria seu modelo utilizando um software diferente das demais, e posteriormente consolidam todos em um único modelo. Este fato pode ser comprovado na análise do Gráfico 2 que mostra os softwares mais utilizados em projetos arquitetônicos e industriais.

Apenas 25\% dos entrevistados compartilham informações de modelos BIM com construtores e fornecedores. A disciplina onde a interoperabilidade está mais desenvolvida é estruturas metálicas em empresas de projetos industriais, no fornecimento de listas de materiais e geração de arquivos CNC para cortes e furos de chapas e perfis. Pode-se inferir, portanto, que a pouca dificuldade relatada com interoperabilidade reside no fato de que as experiências mais significativas com interoperabilidade relatadas acontecem entre softwares especialistas em estruturas metálicas.

Nas empresas de projetos industriais, a escolha das ferramentas BIM é feita conforme a disciplina e/ou exigências do cliente. Por exemplo, a empresa A utiliza para modelamento mecânico o Inventor, mas para modelamento de estruturas metálicas Tekla é o software mais utilizado. Um grande cliente da empresa exige que os modelos sejam entregues no software Smartplant_3D, mas a empresa A concluiu que é inviável a criação de um modelo completo em um único software. Então ela utiliza protocolos de comunicação para consolidar os modelos das diversas disciplinas no Smartplant_3D. Os protocolos adotados são o formato IFC (Industry Foundation Classes) e o SDNF (Steel Detailing Neutral Format).
Segundo o entrevistado da empresa J, a empresa tem que implantar novas tecnologias BIM gradativamente, de forma que não haja paralisações da produção. Nesse contexto, o entrevistado diz que alguns retrocessos e ajustes fazem parte natural do progresso.

O entrevistado B3 afirmou que a empresa B está começando a fazer simulações relativas a tempo de construção, e eficiência energética e incêndio, o que corresponde a um nível mais elevado nas fases de implantação BIM.

Apontou-se um percentual de $72,2 \%$ para tutoriais e fóruns na Internet como o principal meio utilizado no aprendizado das ferramentas BIM. Os profissionais que afirmaram ter feito cursos na fase inicial do aprendizado (27,8\%), nas fases mais avançadas utilizam como recursos tutoriais e consultas a fóruns e aos colegas. Foi possível constatar que a predominância da formação de profissional por tutoriais é característico de um processo de implantação do BIM. Nesse aspecto, observou-se que o conceito BIM está associado à simples utilização de softwares, deixando-se de lado outras questões, como a Gestão do processo de projeto, bem como a integração projeto-obra.

Verificou-se nas entrevistas que o principal motivo que impulsiona um projetista em direção à adoção da tecnologia BIM é manter-se atualizado com as novas tecnologias. Nesse sentido, observou-se que a alta administração das empresas não aderiu à tecnologia por ainda não se conhecer com clareza os benefícios do BIM. O principal motivo de atração das empresas de projetos industriais pela nova tecnologia é a obtenção de mais qualidade de projeto sem preocupação imediata com os custos do projeto.

Entre os principais benefícios alcançados pelas empresas destacam-se a reestruturação e o melhor controle do processo de projeto e melhorias substanciais na compatibilização e coordenação de projetos. Uma das conclusões é a de que o sucesso da implantação de sistemas que melhorem o fluxo da informação intra e extra empresarial está condicionado à melhoria de interoperabilidade dos sistemas, à efetiva consecução de uma cultura de valorização do processo de projeto, ao forte envolvimento dos profissionais e à adoção de metodologias e procedimentos capazes de facilitar a atividade de projeto.

Segundo afirmação dos entrevistados as empresas de projetos industriais estão mais avançadas no processo de implantação da tecnologia BIM, porque projetos de usinas siderúrgicas e mineração, sendo de riscos mais elevados, requerem projetos mais precisos e são mais bem remunerados do que projetos residenciais $\mathrm{e}$ comerciais. 


\section{Conclusão}

O objetivo central da pesquisa foi identificar o estágio de utilização da tecnologia BIM em empresas de projetos industriais e comerciais na cidade de Belo Horizonte. Observou-se que a implantação da tecnologia BIM em projetos industriais em Belo Horizonte está mais avançada do que em projetos arquitetônicos. As empresas de projetos arquitetônicos estão avançando no esforço para sair do estágio da substituição do desenvolvimento tradicional de projetos bidimensionais 2D por modelos 3D parametrizados. As empresas de projetos industriais já estão no estágio de implantação da interoperabilidade.

Entre os participantes do questionário online, observouse que os profissionais de projetos industriais têm uma percepção de valor maior com relação à parametrização, do que os de projetos arquitetônicos. Em termos de motivos importantes para se adotar BIM, a percepção de valor, comparativamente entre projetos industriais e arquitetônicos é similar. Observou-se também que as percepções sobre os impedimentos para a adoção de BIM entre projetistas industriais e projetistas arquitetônicos são basicamente antagônicas.

Nas entrevistas, os profissionais relataram dificuldades nas mudanças nos processos de projeto, e na comunicaçao de dados entre softwares. Verificou-se, nas empresas de projetos industriais, que os softwares sao escolhidos pelas suas características, e não pelo que outras empresas adotam.

Algumas empresas criaram um sistema de treinamento permanente de projetistas na utilização dos softwares, concluindo que, embora percam muitos funcionários para um mercado de trabalho ávido por especialistas em ferramentas BIM, o treinamento é um investimento menor do que buscar um profissional pronto no mercado. Porém a forma de aprendizado dos softwares mais comum ocorre mediante o estudo de tutoriais, consultas a fóruns, troca de informações entre colegas, e principalmente através de vídeo-aulas disponibilizadas na internet.

Foi proposto também pelas empresas entrevistadas, a criação de um proprama de desenvolvimento BIM envolvendo universidades e empresas com incentivo do Governo, para a criação e publicação de documentos e manuais específicos para a implantação da tecnologia BIM, com instruções para projetistas, construtores e demais agentes envolvidos em um empreendimento. Esses documentos poderiam conter também instruções relativas à aplicação dos conceitos de Lean Construction, que, conforme Koskela (1992), são requisitos para maior integração entre projeto e construção

Dentre as propostas de melhorias apresentadas pelas empresas pode se destacar o estímulo ao espírito de cooperação nas equipes de trabalho no que se refere ao compartilhamento de informações e em tomadas de decisões. Destacou-se também a importância do comprometimento da alta direção da empresa para o sucesso da implantação BIM.

De acordo com a pesquisa, o processo de implantação do BIM e a aprendizagem dos softwares é estimado em aproximadamente quatro anos, pois o estudo do software conjuga-se com os aprendizados de engenharia e construção.

Constatou-se que as empresas estão implantando o BIM através do envolvimento da nova geração de profissionais recém oriundos das universidades, enquanto mantêm os engenheiros e arquitetos mais experientes (com perspectiva de aposentadoria em 5 ou 10 anos) apenas gerenciando e transferindo conhecimentos para os mais novos. Constatou-se também nas competências e habilidades desta nova geração de engenheiros e arquitetos, o conhecimento de engenharia de software e programaçao de computadores.

\section{Notas}

(1) Associação Brasileira de Engenharia e Consultoria Estrutural - ABECE, Associação Brasileira dos Escritórios de Arquitetura ASBEA, Instituto dos Arquitetos do Brasil- Departamento Minas Gerais - IABMG, Sindicato da Arquitetura e da EngenhariaRegional Minas Gerais- SINAENCO, Sindicato da Indústria da Construção Civil no Estado de Minas Gerais-SINDUSCON MG, Associação Brasileira de Engenharia de Sistemas Prediais - ABRASIPMG, Conselho Regional de Engenharia e Agronomia de Minas Gerais-CREAMG, Conselho de Arquitetura e Urbanismo de Minas Gerais-CAUMG.

\section{Referências}

ARANTES, Eduardo M.; HOMERO JUNIOR, S.; D’ALMEIDA, Caio S. B. A experiência de implementação do Sistema Colaborativo SISAC para a Gestão de Projetos em uma Entidade Pública. In: ENCONTRO DE TECNOLOGIA DE INFORMAÇÃO E COMUNICAÇÃO NA CONSTRUÇÃO, 5, 2011, Salvador. Anais... Salvador: UFBA, 2011. 
BECERIK-GERBER, Burcin; KENSEK, Karen. Building Information Modeling in Architecture, Engineering and Construction: Emerging Research Directions and Trends. Journal of Professional Issues in Engineering Education and Practice, Reston, v. 136, n. 3, p. 139-147, jul. 2010. Disponível em: <www.ascelibrary.org>, Acesso em: 19 ago. 2014

COMPUTER Integrated Construction Research Program. BIM Project Execution Planning Guide. Version 2.0, The Pennsylvania State University, University Park, PA, USA, abr. 2012. Disponível em: <http://bim.psu.edu/default.aspx>. Acesso em: 21 jul. 2014.

DUBOIS, Anna; GADDE, Lars-Erik. The construction industry as a loosely coupled System: Implications for productivity and innovation. Construction Management and Economics, London, v. 20, n. 7, p. 621-631, 2002. Disponível em< http://dx.doi.org/10.1080/01446190210163543>. Acesso em: 26 ago. 2014.

EASTMAN, Chuck et al. BIM handbook: a guide to building information modeling for owners, managers, designers, engineers, and contractors. Hoboken, NJ: Wiley, c2008. 490 p. :, il. ISBN 9780470185285 (enc.).

KHOSROWSHAHI, Farzad; ARAYICI, Yusuf. Roadmap for implementation of BIM in the UK construction industry. Engineering, Construction and Architectural Management, Bingley, v. 19, n. 6, p. 610-635. Disponível em < http://www.emeraldinsight.com/doi/full/10.1108/09699981211277531 >. Acesso em: 19 ago. 2014

KOSKELA, Lauri. An Exploration towards a Production Theory and its application to Construction. 2000. Dissertation (Doctor of Technology) - University of Technology, Helsinki. Disponível em:

<http://www.vtt.fi/inf/pdf/publications/2000/P408.pdf >. Acesso em: 8 nov. 2010.

KOSKELA, Lauri. Application of the New Production Philosophy to Construction. Stanford: CENTER FOR INTEGRATED FACILITY ENGINEERING, set. 1992. 81 p. (CIFE Technical Report \#72). Disponível em < http://www.ce.berkeley.edu/ tommelein/Koskela-TR72.pdf>. Acesso em: 8 nov. 2010.

LOVE, P.E.D.; GUNASEKARAN, A.; LI, H. Concurrent engineering: a strategy for procuring construction projects. International Journal of Project Management, [s.l.], v.16, n. 6, p. 375-396, dec. 1998, Disponível em:

<http://www.sciencedirect.com/science/journal/02637863>. Acesso em: 26 ago 2014.

PAZLAR, Tomaz; TURK, Ziga. Interoperability in practice: Geometric data exchange using the IFC standard. ITcon, v.13, Special Issue Case studies of BIM use, p.362-380, 2008. Disponível em< http://www.itcon.org/2008/24>. Acesso em: 25 set. 2014.

RUSCHEL, Regina C.; ANDRADE, Max, L. V.; MORAIS, Marcelo. O ensino de BIM no Brasil: onde estamos? Ambiente Construído, Porto Alegre, v. 13, n. 2, p. 151-165, 2013. Disponível em

$<$ http://seer.ufrgs.br/ambienteconstruido/article/view/36881>. Acesso em: 19 set. 2014

SMITH, Dana K.; TARDIF, Michael. Building Information Modeling: a Strategic Implementation Guide for Architects, Engineers, Constructors, and Real Estate Asset Managers. 186 p. John Wiley \& Sons, Inc., New Jersey, USA, 2009.

STEHLING, Miguel P. A utilização de modelagem da informação da construção em empresas de arquitetura e engenharia de Belo Horizonte. 2012. Dissertação (Mestrado em Engenharia) - Programa de Pós-Graduação em Construção Civil, Universidade Federal de Minas Gerais, Belo Horizonte.

TOBIN, John, Proto-Building: To BIM is to Build. AECbytes. Building the future. mai. 2008. Disponível em:<www.aecbytes.com/buildingthefuture/2008/Proto Building. html>. Acesso em: 26 out. 2010. 